\title{
Indonesia antes y después del golpe de Untung
}

\begin{abstract}
W. F. WER T H E I $M$ es profesor en la Universidad de Amsterdam. Entre sus principales publicaciones, están Indone. sian Society in Transition, 1959, y. Sociological Approaches to Modern Asia, 1965.

Este artículo es reproducido de la revista Pacific Affairs (Vol. xxxix. N.os 1-2, Spring-Summer 1966), con autorización del Director.
\end{abstract}

"Para el Occidente es ésta la mejor noticia en muchos años proveniente de Asia". En esta forma calificá la xevista Time en su edición del 15 de julio de 1966, los últimos acontecimientos de Indonesia. La expresión suena algo cínica, considerando que el mismo artículo proporcionaba una espeluznante descripción de los asesinatos en masa que costaron cientos de miles de vidas como consecuencia del golpe de Untung, la llamada Acción "Gestapu" o "30 de Septiembre".

Las víctimas de la matanza en gran escala fueron principalmente comunistas o personas que en mayor o menor grado se identificaron como tales. Fueron ellos los señalados como culpables de la rebelión del 30 de septiembre. El PKI (Partido Comunista de Indonesia) -supuestamente coludido con el gobierno de la República Popular China- ha sido denunciado por la propaganda militar y los otros poderes que actualmente existen en Indonesia como el cerebro maestro del golpe; y de ser responsable del brutal asesinato de seis generales. Otras víctimas del golpe fueron el ayudante de Nasution, teniente Tendean (a quien se confundió con Nasution mismo), la pequeña hija de Nasution y dos altos oficiales en Java Central.

La evidencia histórica a disposición de los investigadores occidentales indica que muy probablemente el golpe de Untung fue precisamente - como lo declaró su líder, el teniente coronel Untung, comandante del batallón de guardaespaldas de Sukarno- un asunto interno del ejército que reflejó las graves tensiones entre oficiales de la División Diponegoro de Java Central y el Comando Supremo del ejército en Yakarta; conflicto durante el cual la Fuerza Aérea se unió a los oficiales de Java Central. El papel de la jefatura del PKI, especialmente del secretario general Aidit, continúa vago y poco claro, 
polfticos iniciales de Sukarno. Aunque este último aún se autocalifique de marxista, él nunca destacó el conflicto de clases dentro de la sociedad de Indonesia. Al contrario, su filosofía social daba más énfasis al hecho de que la gran mayoría de la población de Indonesia se compone de "pequeñas personas" - ya sea campesinos o habitantes pobres de ciudades, como carretoneros o vendedores callejeros- que compartian la misma suerte miserable y sólo eran capaces de ganarse una existencia precaria. Estos marchaens, sin embargo, no eran proletarios en el verdadero sentido, ya que muchos de ellos posefan una cierta independencia económica. La mayoría de los campesinos eran dueños de un pequeño trozo de terreno, su cabaña y unas pocas herramientas agrícolas del tipo más rudimentario.

La ideología de.Sukarno no podrfa llamarse marxista, salvo en un sentido sumamente diluido. El no quiso antagonizar con ningún gran sector de la sociedad indonesia y abogó por. un retorno a un pasado idealizado, en el que los principios de la ayuda mutua (gotong royong) garantizaban la armonía de la vida en la aldea. La filosofía social de Sukarno más bien se ajusta al concepto de "populismo" analizado por Peter Worsley en su iluminador trabajo, The Third Worlda. Este "populismo" es típico de la atmósfera postindependencia, en que todavía el nacionalismo incorpora la disposición de ánimo prevaleciente, y las tensiones sociales y económicas más profundas no están aún suficientemente cristalizadas como para justificar que los dirigentes políticos efectúen un análisis en función del conflicto de clases.

El sincretismo típicamente javanés de Sukarno, unido a su tendencia hacia el debilitamiento de los conflictos internos que aquejaban a la sociedad de Indonesia, lo llevaron a un radicalismo que fue más que nada de palabra antes que de política de acción. Su actitud restauratoria de los valores tradicionales, su irresolución ante la posibilidad de privarse de sectores importantes de la sociedad de su pais, junto al conservantismo siempre en aumento de la máquina gubernamental en la cual debła trabajar el ejército, la administración pública, la burocracia, frustraron casi todos los intentos dirigidos a seguir una política doméstica radical. Aunque cierta cantidad de legislación radical fue introdúcida bajo la presión popular (como, por ejemplo, las leyes sobre reforma agraria de 1960), los elementos conservadores dentro de la administración pública fueron lo suficientemente poderosos como para impedir que éstas fuesen puestas en ejecución en forma efectiva.

epeter Worsley, The Third World, Londres, 1964. 
Además, la debilidad fundamental del planteamiento ideológico de Sukarno, que lo llevaba a destacar los valores espirituales y polfticos y despreciar la eficiencia económica, afectó gravemente la capacidad de su administración para hacer frente a los problemas básicos de una economía subdesarrollada. La creciente escasez de material unida a la corrupción del gobierno produjeron un descontento latente en las masas y una pérdida del patriotismo idealista entre la juventud.

Durante muchos años el régimen de Sukarno intentó compensar su falta de éxito en el campo doméstico con un incrementado radicalismo en la politica internacional. Las violentas criticas hechas por Sukarno al imperialismo y neocolonialismo, sus medidas extremas en contra de la inversión extranjera, su mayor dependencia de las armas soviéticas y sus públicas alabanzas a la República Popular China, fueron elementos de su política que se combinaron para evocar una visión de la Indonesia anterior al golpe como una nación a punto de tornarse comunista. Quienes asi opinaron, sin embango, erraron profundamente en cuanto a la verdadera situación.

El Partido Comunista de Indonesia distaba mucho de estar en posición que le permitiese siquiera intentar obtener el poder, a pesar de que el PKI contaba con gran cantidad de miembros en sectores muy importantes del pafs. El verdadero poder de los comunistas estaba severamente restringido dentro de la estructura Nasakom, tal como ésta se ejecutaba en la práctica. Primero, se vieron confrontados no solamente con un poderoso grupo religioso (casi totalmente representado dentro del gobierno de Indonesia por el partido tradicionalista Nahdatul Ulama), sino también con el ejército que se dirigia rápidamente, como en tantas otras sociedades postcoloniales, hacia la formación de un estado dentro del estado. El ejército era el dueño de las armas, no los comunistas; y el ejército se mantuvo intransigente respecto a la petición comunista de formar una "Quinta Fuerza", una milicia armada a la cual se entrenarła como ejército voluntario que eventualmente reforzase la polftica de "Confrontación" contra Malasia.

Desde el primer momento que Sukarno formuló su concepto $\mathrm{Na}$ sakom, tanto el ejército como el Nahdatul Ulama se opusieron tenazmente a la formación de un gabinete Nasakom. Lo máximo que pudo lograr Sukarno fue nombrar como ministros sin cartera a varios de los principales líderes comunistas, lo que los excluía de toda autoridad dentro de la estructura burocrática.

En los escalones más bajos del instrumental gubernativo, como gobernadores, alcaldes o representantes políticos, el PKI tenía inter- 
vención. A pesar de esto, su poder político estaba en todo momento equilibrado por poderes antagónicos que no deben ser menospreciados. $\mathrm{Y}$ aunque existieron amplias sospechas de que Sukarno favorecía a los comunistas, existen suficientes indicios que comprueban que, en la realidad de los hechos, el equilibrio de poder que hemos mencionado respondía precisamente a los deseos de Sukarno. No es sin motivos que algunos escritores, y especialmente Donald Hindleyt, han argumentado que lo verdaderamente logrado por Sukarno con su polftica Nasakom fue domesticar al PKI. Para poder ser aceptados como participantes dentro del gobierno, los comunistas tuvieron que moderar gran parte de su radicalismo social y politico. Al hacerlos compartir la responsabilidad gubernativa, Sukarno efectuó una maniobra que colocaba a los comunistas en una posición bastante precaria si acaso deseaban criticar la política oficial. A lo largo de varios años, el PKI se había opuesto a algunas de las medidas económicas de la administración de Sukarno, pero obraban siempre bajo la presión de evitar un distanciamiento del Presidente mismo. Cualquier influencia que hayan tenido los comunistas sobre Sukarno, se refirió al campo de la política internacional y no al de la interna. Incluso - las críticas hechas a la corrupción oficial se tornaron más difíciles, dada la responsabilidad compartida por el PKI dentro del gobierno. Anteriormente, el PKX había mantenido su reputación como incorruptible en momentos en que prácticamente todos los demás partidos políticos estaban seriamente comprometidos por su conducta viciada. Aunque en el período pregolpe la reputación comunista, en este sentido, continuaba siendo mucho mejor que la de cualquier otro grupo, incluyendo al ejército, no todos los líderes comunistas que desempeñaron cargos oficiales lograron resistir las tentaciones del poder.

¿Por qué motivo, entonces, los comunistas aceptaron las limitaciones que acatar el concepto Nasakom de Sukarno implicaba? ¿No perdían acaso lo mismo, en cohesión interna y claridad de intención, que lo ganado en verdadero poder? Es muy probable que la aceptación del concepto de Sukarno fuese una precondición a su existencia legal. Las medidas que tomó Sukarno después de 1958 en contra de los partidos políticos concordaban con su filosofia polftica. El PKI consideró una victoria el hecho de que Sulkarno tolerase la existencia de una cantidad restringida de partidos dentro de la estructura de democracia guiada que él propuso.

¿Donald Hindley, The Communist Party of Indonesia, 1951-1963, Berkeley y Los Angeles, 1965; Herbert Feith, Dynamies of Guided Democracy; en Ruth T. MeVey (ed.), Indonesia, New Haven, 1963, p. 340; Jan M. Pluvier, Confrontations; A Study in Indonesian Politics, Kuala Lumpur, 1965. 
Pero la aceptación de la coalición Nasakom armonizaba también con un concepto táctico bien conocido en el mundo comunista. En la década de 1920, el Comintern había defendido una política de bloque interno para los partidos comunistas de Asia5. Esto significaba que, en situaciones en que el Partido Comunista no fuese suficientemente poderoso o fuerte como para seguir una política auténticamente socialista, debido a la situación de subdesarrollo de la economía rural, debía entrar en alianzas con los grandes movimientos nacionalistas. La cooperación entre el Partido Comunista de China y el burgués Kuomintang se consideró, en esa época, como el modelo para una alianza de este tipo.

Igualmente, en Indonesia el PKI había en un principio intentado cfectuar esta alianza con el Sarekat Islam. Alrededor de 1922 esta alianza terminó debido a graves conflictos tanto ideológicos como personales. Los fervientes musulmanes pertenecientes al Sarekat I.slam perdieron la paciencia ante el ateísmo secular típico del marxismo. Además, un potencial conflicto de clases entre los capitalistas nativos y el proletariado se anunció en estas disputas que llevaron a la ruptura de la alianza temporal. En momentos que el Comintern todavía urgía al PKI hacia una vuelta a la politica de coalición y hacia la disminución de sus críticas de los jefes del Sarekat Islam, los comunistas indonesios se dirigian ya hacia la frustrada rebelión de 1926-27.

El resultado de la política de bloque interno no fue menos catastrófico en China. En 1927, Chiang Kai-shek desbandó enérgicamente la coalición y los comunistas se encontraron reducidos a una existencia precaria $e$ ilegal. Por lo tanto, es comprensible que Mao Tse-tung, utilizando su experiencia, modificase radicalmente el concepto de bloque interno. En su opinión, las alianzas con nacionalistas burgueses son solamente aceptables si los comunistas se preocupan especialmente de mantener el control de la coalición.

Esto es lo que jamás hizo el PKI en el periodo anterior al golpe. Dentro de la coalición era más bien el miembro más débil, quedando la iniciativa y decisiones finales en manos del Presidente. Una de las paradojas de la reciente historia de Indonesia es que, ideológicamente, el PKI - e incluso hasta la administración misma de Sukarnose encontraba bastante próximo a la posición de Pekín en asuntos internacionales; pero, en la práctica, la política del pki distaba nucho de los preceptos de Mao. Los chinos seguramente esperaban el derrumbe final de la estrategia del PKI, aunque, debido a razones de

\footnotetext{
"Para muchos detalles ilustrativos, ver el brillante estudio de Ruth MeVey, The Kise of Indanesian Communism, Ithaca, 1965.
} 
política internacional, continuaron celebrando a Indonesia y su Presidente como a un vecino amistoso y bienvenido aliado.

En consecuencia, es muy poco probable que el gobierno de China haya tomado parte en el golpe de Untung. Uno puede imaginarse que habrian apoyado un golpe que sirviera a los comunistas para apoderarse de la jefatura de la coalición. Difícilmente podían respaldar el golpe de un grupo militar que creó un consejo revolucionario donde todavía se reflejaba la composición Nasakom que relegaba al PKI a un papel menor y además se le mantenia sujeto al control de una junta militar.

Mucho más probable es la historia que oí en Indonesia en 1.957. Se decia que Mao Tse-tung le había preguntado a Aidit durante su visita a Pekín: "Bueno, ¿cuándo será el día que te decidas a retirarte a las montañas?". El gobierno de China pudo haberse tornado menos neutralista y haber aumentado su apoyo a la posición de Indonesia en asuntos internacionales. Pero difícilmente se puede creer que los chinos esperasen que el caso de Indonesia resultara una excepción a su concepto general sobré la forma en que un partido comunista puede llegar al poder.

Por consiguiente, quienes consideren que el asunto de Untung y su secuela fue un fuerte golpe a la política china, tienen razón solamente en cuanto a la posibilidad de que China contase con una alianza continuada todavía por algún tiempo; pero no se puede creer que los chinos confiaran en el concepto Nasakom como una fórmula de acción permanentemente adecuada para Indonesia. Ellos, sin lugar a dudas, sabían que, llegado un momento dado, el PKI verdaderamente tendría que retirarse a las montañas.

¿Por qué ocurrió el choque inevitable en 1965? La razón más importante es que el campesinado pobre se impacientaba y ya no se podía evitar que expresara sus quejas sobre necesidades que no se ajustaban dentro de la ideología "marhaenista" ni dentro del molde político Nasakom. En 1964 se pudo observar claramente que la legislación sobre reforma agraria demoraba su puesta en ejecución debido al sabotaje de un gran sector de la administración pública. La unión de campesinos, BTI, afiliada al PKI, inició un movimiento para obligar al cumplimiento de la legislación por medio de acciones unilaterales, las Ilamadas aksi sepihak. Utilizaron a sus miembros y habilidades organizativas para dividir la tierra de acuerdo con las disposiciones legales, pero haciendo caso omiso del procedimiento legal correspondiente. Casi simultáneamente, el PKI desató una campaña contra los denominados "siete demonios de las regiones rurales". Entre estos demonios, tal como los definió Aidit, estaban los 
pérfidos terratenientes que se negaban tanto a cumplir con la ley agraria fundamental como con la de contratos de mediería; los usu. reros e incluso los compradores de brotes de arroz.

Evidentemente, el PKI no tuvo conciencia suficiente de que iniciando estas campañas en contra de los grandes terratenientes, abandonaba el socialismo diluido de Sukarno y adoptaba una claramente perfilada posición de lucha de clases. Inevitablemente, con esta actitud alejaría irrevocablemente a sus compañeros musulmanes en la coalición Nasakom, el Nahdatul Ulama, que en Java Central y Orien. tal representaba principalmente a la clase teriateniente pudiente.

Es muy posible que la diferenciación social y económica y las tensiones de clases en las zonas rurales hubiesen alcanzado, en 1964, una etapa en la que una polftica de acomodo de los grandes propietarios y de alivio del conflicto de clases ya no resultaba factible. E] deterioro de la economía de Indonesia, el siempre creciente número de trabajadores rurales sin tierra alguna, o con una cantidad insignificante y principalmente la progresiva involución de la economf́a del arroz en Java ${ }^{6}$, obligaron a los representantes populares a asumir una actitud más radical. Evidentemente, la jefatura del PKI no se dio cuenta de que este giro en su politica rural significaba una clara desviación del concepto Nasakom aún oficialmente adoptado tanto por el Presidente como por el Partido Comunista. Sin embargo, su seria confrontación con los santris rurales durante el Asunto Madiun de 1948 debió advertir a los lideres del pKI sobre lo que sucedería en cuanto el conflicto de clases rural surgicse abiertamente.

Los choques no tardaron en producirse. En el transcurso de 1964, se produjeron reyertas entre musulmanes y comunistas en varios lugares de Java Oriental. Aunque la motivación reconocida era frecuentemente ideológica y religiosa, no era difícil descubrir los puntos en disputa subyacentes: económicos, sociales o políticos. Las escuelas islámicas no sólo eran focos de agitación contra el comunismo y el ateísmo, sino que también estaban muy influidas por los campesinos más ricos como conjunto de intereses. Lance Castles ${ }^{7}$ describe una escuela islámica en la zona de Ponogoro (en la parte occidental de Java Oriental, no lejos de Madiun) donde la matrícula era de 5.000 rupias al mes, cantidad que implicaba que los alumnos, los santris, provenían de las familias de aldeanos más ricos. Un informante dijo a Castles que "muchos de sus ex alumnos eran campesinos y muchos también poseian más tierras que el máximo establecido por

\footnotetext{
over Clifford Gecrtz, Agricullural Involution: The Processes of Ecological Change in Indo. nesia, Berkeley y Los Angeles, 1963.

iLance Castles, Notes on the Islamic School at Gontor, Indonesia, No I, abril 1966, desde p. 30 .
} 
la ley". Una gran cantidad de alumnos venia de Djember (Java Oriental) o de Klaten (Java Central), contando ambos distritos con muchos campesinos ricos y cultivando ambos el más bien capitalista producto del tabaco. En ambas zonas se desarrollaron conflictos șociales agrarios durante 1964 y 1965. El conflicto en Klaten fue debido a los esfuerzos de la BTI para ejecutar la reforma agraria unilateralmente"8. No había ningún alumno que viniese de alguna de las paupérrimas regencias rurales de Java Central, tal como lo especifica Castles. El menciona a su vez la reacción de los terratenientes ante la legislación sobre reforma agraria. El efecto inmediato se habia manifestado en súbitas donaciones de grandes extensiones de terrenos a la escuela, como wakf (un ofrecimiento religioso musulmán). La actitud prevaleciente en la escuela era de oposición a la reforma agraria.

En diciembre de 1964 los líderes del PKI fueron instados por Sukarno, el Nahdatul Ulama y el PNI nacionalista a detener el movimiento aksi sepihak. Parece que alguna promesa existió, pero al parecer los líderes del PXI difícilmente podian. ya contener a sus partidarios rurales. Parece, sin embango, que durante los meses que precedieron al golpe, el movimiento había perdido gran parte de su impulso. Pero las consecuencias políticas fueron irreparables.

Si la jefatura del PRI persistió, incluso durante los fatales primeros dias de octubre, en expresar su lealtad hacia Sukarno y su fe en Nasakom, fueron sus principales opositores, los fervientes gxupos musulmanes, los que iniciaron una verdadera lucha de clases. La cacería roja, dirigida por el ejército en Java Occidental -y en la mayoría de los pueblos más grandes- podría ser interpretada como el choque de dos élites en competencia. Tal como en ocasiones anteriores, grupos de estudiantes izquierdistas habłan presionado por medio de demostraciones públicas y exigiendo el despido de los oficiales que hubiesen provocado.su ira; ahora otros grupos estudiantiles, apoyados por el ejército, imponfan sus exigencias y aterrorizaban a quienquiera que cayera bajo sospechas de opinar distintamente. El terror fue más grande que durante el periodo anterior، al golpe si se considera la enorme cantidad de prisioneros políticos hacinados en cualquier recinto que sirviera de prisión. A pesar de todo, lo sucedido en Java Occidental y en los pueblos más grandes es insignificante si se compara con. la gigantesca matanza efectuada en las distintas regiones rurales de Java Central, Java Oriental y Bali.

Los asesinatos comenzaron el 20 de octubre en la región de Klaten mencionada más arriba, después que las tropas de asalto y las uni-

Oobra cil., p. 38. 
dades de la División Siliwangi de Java Occidental habían sido enviadas a Java Central y que los fanáticos musulmanes empezaron a sentir mayor confianza. Hasta este momento, la jefatura del PKI había mantenido su política de adhesión a la más estricta legalidad. Ahora, los comunistas observaron claramente que una actitud obediente de las leyes $y$ el hecho de haber evitado cualquier acción que se hubiese consicleraclo como una provocación al ejército habían sido absolutamente inútiles. El ejército habia decidido, sucedieșe lo que sucediesc, aplastar y eliminar al partido. El PKI recordaba bien la actuación de la División Siliwangi Sudanesa (orientada más abiertamente hacia Islam que la División Diponegoro de Java Central) durante la represión de la insurrección de Madiun en 1948. La disciplina jerárquica del PKr comenzó a clesmoronarse debido al arresto o persecución de muchos líderes. Ciertos elementos temcrarios decidieron intentar mantener una posición dentro del triángulo formado por Solo-Bejolali-Klaten, en la región montañosa de Merapi-Merbabu. Se desarrolló una corta $y^{\prime}$ feroz guerra civil, salvaje si se compara con la insurxección de 1958 en las Outer Islancls. Esta última rebelión implicó mucho más peligro para la integridad del estado de Indonesia, sin embargo, la represión efectuada por las tropas de Nasution fue ejecutada de tal manera que permitió a un periodista británico describirla como "la guerra civil más civilizada de la historia humana". Pero ahola las uniclades del $\mathrm{skr}$ que luchaban en las montañas sin arma alguna se encontraban indefensas ante las bien pertrechadas tropas de asalto, ayudadas por jórenes musulmanes armados por el ejército. En esta ocasión el ejército no tuvo por qué temer a la "Quinta Fuerza".

La resistencia comunista muy pronto se rompió y los asesinatos en masa comenzaron a extenderse dondequiera apareciesen las tropas de asalto. Lo sucedido en Java Oriental y Bali fue tal vez más espantoso que todas las atrocidades cometidas en algunas partes de Java Central. No detallaremos la matanza sino que nos concentraremos aquí en el esquema fundamental.

Kediri (Java Oriental) fue una de las zonas donde la matanza asumió proporciones de masacre. Seymour Topping relata que "la mayoria de los asesinatos fueron ejecutados por patrullas de Ansor (una organización juvenil musulmana) adiestradas por el ejército; principalmente adolescentes o personas en sus primeros veinte años que asistian a la universidad musulmana y escuelas religiosas del clistrito de Kediri"'. Un riejo líder religioso opinó que los asesinatos eran la voluntad de Dios; al mismo tiempo él dijo que Ansor había

"New York Times, agusto 24, 1966. 
"cumplijo con las órdenes del ejército". "El tenía dos quejas espe. cfficas contra los comunistas: que ellos hubiesen 'actuado unilateralmente en la redistribución de tierras y que hubiesen ofendido a los musulmanes".

¿Por qué se unió el ejército a los terratenientes más ricos? El artículo de Topping rosiblemente nos da un indicio: "En el primer día de la matanza, un oficial del ejército, vestido de civil, abandonó alegremente la ciudad de Kediri portando una ametralladora para disparar contra unos colonos usurpadores que se habian negado a salir de sus campos no cultivados". Topping agrega: "Hubo aljunos cstallidos en las aldeas contra los miembros del Partido Comunista que habian supervigilado la ejecución del reparto de tierras y de la législación sobre contratos de mediería". Lo sucedido en la zona de Banjumas (Java Central) muestra un esquema similar ${ }^{10}$. In el período anterior al golpe, "el Partido Comunista lenta, pero seguramente, socavaba al Partido Musulmán. Los comunistas habłan tomado muchos campos de caña y los habían transformado en arrozales para sus partidarios y los campesinos más pobres, quienes ahora jamás los entregarían". En octubre la carnicería fue iniciada, principalmeinte por jóvenes musulmanes que usaban sus cuchillos segadores de caña o armas que habían recibido del ejército o de la guardia del pueblo. El pкI en Banjumas "era numeroso, pero no fuerte. Sus miembros estaban compuestos por los campesinos más pobres. Generalmente se adherían porque los comunistas les ofrecían tierra. y.la oportunidad de cultivar su propio arroz".

Don Moser, en un artículo en Life ${ }^{11}$ trata de mostrar un cuadro algo diferente, pero su hístoria esencialmente confirma la opinión de más arriba: "En muchạs regiones rurales los comunistas habian introducido el nuevo programa de reforma agraria en forma muy mal administrada. Se suponía que el programa distribuia la tierra en forma équitativa, peio los comunistas no solamente se apoderaron de tierras pertenecientes a miembros muy respetables de la comunidad, sino que además intentaron tomar tierras de propiedad de las mezquitas musulmanas". Esta última acción seria comprensible.si, tal como lo explica Lance Castles, una gran cantidad de terrenos hubiese sido transferida a nombre de las mezquitas para evadir la legislación de reforma agraria.

En regiones no musulmanas, los terratenientes más grandes a veces obedecían a otras denominaciones religiosas. De acuerdo con cier-

${ }^{20}$ El periodista australiano Frank Palmos en The Sun, agosto 5, 1966; reimpreso anónimąmente en The Econonitist, agosto 20, 1966.

11Life, julio 1966. 
ta información digna de confianza que obtuve de un colega australiano, en Timor de Indonesia "más de 3.000 personas han sido muertas, en este caso no por extremistas musulmanes sino que por racljahs católicos y grandes terratenientes aliados con el comando militar". En la indoísta Bali la situación fue más complicada. El grupo terrateniente estaba principalmente orientado hacia el PNr. Allí la matanza fue generalmente efectuada. por juventud del PNI, respaldada por las tropas de asalto, aunque el Comandante Sarwo Edhie sostienc que, una vez que sus unidades llegaron, la matanza terminó. Sin embargo, en esa isla el PKI no era un partido basado principalmente en un proletariado campesino, como en el resto de Java. A pesar de esta circunstancia, incluso allí el PKI había iniciado "acciones unilaterales" hacia la redistribución de la tierra entre las víctimas de la erupción volcánica del Ganung Agung, quienes intentaban subsistir por medio de cultivos en mediería. En la parte occidental de la isla, la casi totalidad de la matanza fue efectuada por jóvenes musulmanes que habían cruzado el estrecho de Bali desde el extremo oriental de Java (Banju-wangi), también una zona azoiada por el terror general.

También existen aquí indicaciones de que el problema de la tierra determinó básicamente los asesinatos en masa. De acuerdo con una fuente de confianza, en algunas zonas el problema que se produciría a largo plazo se complicó aún más con la toma-de terrenos en producción de personas que estaban bajo arresto. En diciembre de 1965, el Ministro cle Asuntos Agricolas afirmó que "la puesta en marcha de la reforma agraria ha sido entorpecida por las consecuencias negativas del movimiento contrarrevolucionario '30 de Septiembre" ". Ese ministerio todavía continuaba "decidido a que la redistribución de tierras a los campesinos sin terrenos debía realizarse de acuerdo a las disposiciones legales, y a tomar medidas drásticas contra los propietarios u otros elementos que se aprovechan de las operaciones de exterminio de la 'Gestapu' para recuperar terrenos ya redistribuidos o para demorar la redistribución"12. El comentarista agrega: "Claramente, la realineación inicial de las fuerzas políticas que siguió al golpe y destrucción dẹl Partido Comunista fortaleció por lo menos temporalmente la posición de los grupos opuestos a las reformas agxarias planificadas".

Esta declaración es confirmada por el profesor Daniel Lev de la Universidad de California: "El Nahdatul Ulama, por ejemplo, ha sido franco en su alegría ante el hecho de que, no existiendo el PKI,

\footnotetext{
12Bulletin of Indonesion Economic Studies, Australian National University, No 3 (febrero 1966), p. 17.
} 
la reforma agxaria y otros esfuerzos similares pueden ahora ignorarse del todo"13. Una noticia aparentemente confidencial (pero de hecho solamente hipócrita) fue publicada por la agencia noticiosa Antara a través de su oficina en Colonia, el li4 de marzo de 1966: "La administración de Java Central anunció que 32.156.428 hectáreas de terreno fueron redistribuidas a 128.534 campesinos en Java Central" (jesto significaría más de 200 hectáreas por persona en un país donde un hombre que posea cinco hectáreas se considera como un gran terrateniente!). "Fuentes informadas declararon que los campos entregados a ex miembros del BTr, o bien a otras onganizaciones afiliadas al Partido Comunista, están actualmente siendo devueltos por ellos a sus antignos propietarios. Ellos sostienen que la reforma agraria y redistribución de los campos fue una iniciativa del PKI y que, actualmente, después del movimiento contrarrevolucionario ' 30 de Septiembre, ya no quieren seguir teniéndolos". Uno se permite cludar si acaso Antara notó la amarga ironía de esta información.

El argumento más arriba expuesto no descarta la posibilidad cle que en ciertas regiones y en ciertos casos específicos las condiciones económicas y sociales hayan diferido del esquema descrito. Consecuentemente, la alineación de fuerzas puede haber sido distinta algunas veces de la tendencia general aquí expuesta. También es cierto que la gran mayoría de la población de Indonesia cree que el PKI fue el cerebro maestro y ejecutante del golpe y sus brutalidades. Igualmente es probable que muchas personas creyeran en la existencia de listas de personalidades prominentes y lideres religiosos que serian asesinados si el golpe tenía éxito. Seymour Topping declara, en sus artículos para el New York Times, que "la mayoría de los observadores experimentados cree que estas historias han sido inventadas debido a la necesidad de racionalizar los asesinatos en masa. No existe evidencia. sustancial alguna de que los comunistas contasen con grandes abastecimientos de armas o planearan una gran insurrección nacional para apoderarse del poder total en el futuro próximo". Pero muchos de los homicidas pueden haber creido lo que se les decía: "eran' ellos o nosotros"14.

A pesar de esto, la extrema crueldad y la escala masiva de los asesinatos, así como su distribución regional, junto al impacto de la puesta en marcha de la reforma agraria, son factores que no pueden ser explicados sin tomar en cuenta el conflicto de clases básico como la característica de los acontecimientos.

ssDaniel S. Lev, obra cil., p. 110.

1'Bridget Mellor, Political Killings in Indonesia, New Statesman, agosto 5, 1966. Sutter (ver nota 1), se refiere a las "listas negras" del $5 \mathrm{KI}$ en 1965 , sin siquiera dudar de su autenticidad (obra cil., p. 542). 
Aunque asi sea, los comunistas obligadamente han sido relegados a la ilegalidad en la actualidad. Si algunos de ellos aún cucntan con el Presidente, construyen sobre arenas movedizas, o más bien, se apoyan en un débil títere de vitrina. El Presidente comprobó, durante la larga ocupación japonesa, hạsta qué extremos de sumisión está dispuesto a llegar si se le permite mantener las apariencias de autoridad y a la vez esperanzas de un futuro resurgimiento ${ }^{15}$. Además, él ahora tiene sus palacios y algunas de las alegrías y lujos que odia sacrificar. Su resistencia verbal ante los jefes del ejército que actualmente ejexcen el poder no ha resultado efectiva, hasta aquí.

No caben dudas de que en el futuro la lucha de clases volverá a interesar al campesinado pobre, en cuanto sus líderes puedan reorganizarse y calcular una nueva estrategia. No es posible imaginar que el gobierno actual será capaz de solucionar los problemas económicos básicos que persiguen a Indonesia. Asesinar a cientos de miles de personas no soluciona el problema de la falta de tierr:i; tampoco el asesinato de toda la parentela de una víctima, incluyenclo a los niños que podrian transformarse en vengadores en potencia, puede impedir el surgimiento de una nueva clase de personas necesitadas de tierra que eventualmente levantarán el estandarte de la rebelión y la venganza. El respalclo dado a la posición de los terratenuentes más ricos difícilmente moverá a la gran mayoría de ellos a tratar cle aumentar la producción rural. Indonesia goza en este momento de lo que Alers ha llamado "una merdeka verde", en lugar. de una roja ${ }^{16}$. El color verde simboliza la alianza de los musulmanes con las fuerzas feudales. El Islam ha logrado funcionar $\mathrm{cn}$ todo el tercer mundo como una ideología suficientemente fuerte como para resistir el impacto del pensamiento marxista y la acción revolucionaria. Ningún país islámico (excepto los que se encuentran dentro de la órbita del poder soviético) ha sucumbido hasta hoy día ante el marxismo, en gran parte debido a las tradiciones anticoloniales y antiocciclentales típicas del mundo de Islam.

Pero la situación podría cambiar de la noche a la mañana ji acaso el Islam, tal como lo ha hecho en Indonesia, se alinea con las fuerzas de la reacción social y se transforma en el estandarte ba-

\footnotetext{
25er: Sukarno, An Autobiography, contada a Cindy Adams, Indianapolis y Kansas City, 1965, m. 192-193.

${ }^{10}$ Henry J. H. Alers, $O m$ cen rode of groene merdeka: 10 jaren biunenlandse politiek; Indonesië 1943-1953; Eindhoven, 1956. Mferdeka significa libertad. Alredecior de 1925, en Java Occidental, micinbros de la adininistración pública de Indonesia estimularon la creación del Sarekat IIidjau (sindicatos verdes) para contrarrestar la influencia del Sarckat Merah (sindicatos rojos) que formaron la base rural del pKr. La actual estructura del poder en Indonesia es llamada por el hombre de la calle una "ampat hidjau"; "los cuatro verdes son el color de Islam; de las boinas de las tropas de asalto; de la unión estudiantil reaccionaria, kasr; y, último pero no tanto, del Embajador norteamericano, Marsliall Green".
} 
jo el cual los que tienen luchan contra los que no tienen. Ahogar las reformas agrarias jamás han resultado ser, en Asia por lo menos, el modo de solucionar los problemas económicos. No hay signo alguno de que el actual gobierno que, a pesax de tocla su terminologia democrática, demuestra poseer muchas cualidades típicas del fascismo militar, esté logrando gran éxito en la solución realista de ni siquiera un solo problema económico específico. La corrupción continúa siendo tan desenfrenada como siempre.

Lo sucedido en Indonesia se considera en algunas partes como un golpe a la República Popular de China. En realidad, más bien puede considerarse como un golpe a la Unión Soviéticá. Fue el concepto soviético de "democracia nacional" (que, según se afirma, allanaría el camino hacia una transición gradual no revolucionaria hacia el socialismo, con la ayuda del gobierno de la Unión Soviética) el que se puso a prueba en Indonesia el año pasado17. Los acontecimientos probaron alli, si algo probaron, que el. camino revolucionario sin violencia se bloquea en el momento mismo que se alcanza la etapa de lucha de clases. Puede que el PKI haya aprendido la lección después de los hechos: tal como Mao lo ha expresado, "el poder po: lítico surge desde el cañón de un arma de fuego".

La situación presente, un año después del golpe, puede ser comparada con la situación de China en 1928, un año clespués que Chiang Kai-shek se hubiera súbitamente vuelto en contra de sus antiguos aliados en la expedición del norte y aplastara al Partido Comunista Chino. Un marxista holandés muy conocido, el fallecido ingeniero $\mathrm{S}$. J. Rutgers, quien viajó mucho y conoció varios países asiáticos, analizó lo sucedido en China en un libro terminado en agosto de 1928.

"La expedición del norte fue, cuando todavín los burgueses se unían a los trabajadores y campesinos, una marcha triunfal casi sin sangre, pero al mismo tiempo fue un recurso que reforzaría enormemente el impulso revolucionario y poder organizativo de las poblaciones rurales y urbanas.

En vista de las exigencias provenientes de los obreros de Shangai para formar una fuerza armada independiente, y bajo las amenazas de los imperialistas extranjeros, muy pronto una parte importante de la burgueșia china, estrechamente atada a los imperialistas por intereses materiales, traicionó al movimiento nacionalista. Menos plausible es la rapidez con que el ala izquierda del Kuomintang les siguió en esta traición. Quienquiera estudie la literatura escrita sobre el corto periodo existente entre las traiciones de Chiang Kai-

\footnotetext{
27Ver por ejemplo, V. I. Pavlov, India: Econontic Freedom versus Imperialism (taaducido del ruso), Nucva Delhi, 1963.
} 
shek y de Hankow, no puede evitar sentirse impresionado por lo poco que pesan las palabras cuando hay que confrontar los factores fundamentales del conflicto de clases. Solamente si se observan las fuerzas enormes e indomables que se expresaron por medio de las rebeliones campesinas del sur de China, y al mismo tiempo se toma en cuenta la manera en que los diferentes estratos de la burguesía china tienen un interés creado -alquileres y ganancias usurarias pagados por las aldeas- puede uno comprencler en su totalidad esta caida total y casi repentina del ala izquierda de la burguesía china, a pesar de todos los 'ideales' profesados anteriormente respecto al nacionalismo y sunyatsenismo"18.

Rutgers concluyó con una previsión verdaderamente misteriosa: "El factor principal radica en que la burguesia china es absolutamente incapaz de efectuar reforma agraria alguna de manera siquiera moderadamente eficaz. Por otro lado, las condiciones en el campo son tales que excluyen toda posibilidad de que el movimiento revolucionario puecla apaciguarse en esas partes. En realidad, los trabajadores, ayudados por algunos sectores de estudiantes y otros elementos rebeldes de los pueblos, han adquirido ya suficiente fuerza como para poder asumir el liderato de un movimiento revolucionario generalizado y así ạlcanzar una victoria final". La semejanza de lo aquí descrito con la actual situación de Indonesia es evidente.

El análisis precedente establece claramente que muy pocos asiáticos tendrían una tendencia a considerar los acontecimientos dentro de Indonesia que se desencadenaron después del golpe como "la mejor noticia en muchos años". También agregaria que celebrar lo sucedido en Indonesia desde el punto de vista occidental igualmente indica una ausencia de comprensión de cuáles serfan los verdaderos intereses occidentales para el futuro. La estimación de los hechos realizada por la revista Time, resumida en la frase: "para el Occidente es esta la mejor noticia en muchos años proveniente de Asia", resultó ser no solamente cínica sino que, por añadidura, carente de visión.

165. J. Rutgers, Het boereneraagstuk in Sovjet-Rusland; Europa, Amerika,'Indï̈, Chinal Rotlerdami, 1929, pp. 125-126. 